\title{
The 2020 International Workshop on Statistical Genetic Methods for Human Complex Traits (Formerly the 'Methodology of Twin and Family Studies Introductory Workshop')
}

๑) Springer Science+Business Media, LLC, part of Springer Nature 2019

\section{March 2nd-March 6th, 2020}

The next workshop will be held in Boulder, Colorado, March 2nd-6th, 2020. The course is planned to include sessions on: causes of variation; biometrical genetics; OpenMx: regression, path analysis, matrix algebra, optimization; univariate twin analysis; ACE modeling; binary and ordinal data; multilevel modeling; between group heterogeneity; continuous heterogeneity, sex limitation and $\mathrm{G} \times \mathrm{E}$ interaction; multivariate models and genetic analysis; GREML; genomic SEM; developmental models; direction of causation modeling; polygenic risk scores; Mendelian Randomization; statistical power; responsible conduct of research.

Hands-on analysis will be emphasized, using the networked notebook computers provided. We have traditionally used OpenMx, developed by Dr. Michael Neale \& colleagues for the flexible analysis of genetically informative data, and R programming. The OpenMx website is: https:// openmx.ssri.psu.edu/. A beginner's guide to OpenMx is at: https://vipbg.vcu.edu/vipbg/OpenMx2/docs//OpenMx/lates t/NewBeginnersGuide.html

Participants are strongly advised to have some familiarity with $\mathrm{R}$ programming before attending the workshop. For those not familiar with $\mathrm{R}$, you should take advantage of the many introductory $\mathrm{R}$ tutorials available online.

Michael Neale serves as the Academic Director for the workshop and Sarah Medland as Associate Director.

An outstanding international faculty roster includes:

Michael Neale (Academic Director), Nathan Gillespie,

Rob Kirkpatrick, Hermine Maes, Joshua Pritikin. Virginia Institute for Psychiatric and Behavioral Genetics. Virginia Commonwealth University, USA

Sarah Medland (Associate Director), Lucia Colodro Conde, Jose Garcia, Katrina Grasby, Nick Martin. QIMR Berghofer Medical Research Institute, Australia John Hewitt and Matt Keller (Local Hosts), Jeff Lessem, Luke Evans. Institute for Behavioral Genetics, Boulder, CO, USA
Brad Verhulst. Texas A\&M University, USA

Elizabeth Prom-Wormley. Dept. of Family Medicine and Population Health, Virginia Commonwealth University, USA

Ben Neale. Analytic and Translational Genetics Unit, Massachusetts General Hospital, USA

Meike Bartels, Dorret Boomsma, Conor Dolan, Camelia Minica, Michel Nivard, Evelin de Zeeuw. Amsterdam Vrije Universiteit, Netherlands

David Evans. University of Queensland Diamantina Institute, Australia

Timothy Bates. University of Edinburgh, Scotland, United Kingdom

Stacey Cherny. Tel Aviv University, Israel

Mike Hunter, Georgia Institute of Technology, USA

The registration fee is $\$ 600$, payable by January 24th, 2020. Thereafter, the fee will be $\$ 700$. Non-payment by February 14th, 2020, will result in your registration being dropped, and cancellations after that date will be nonrefundable. Further information and details of local arrangements, registration, and accommodation are available at https://www.colorado.edu/ibg/workshop-2020 and from the workshop coordinator, Katie Sheehan, IBG, telephone: 303492-6057; e-mail: IBGworkshop@colorado.edu

Individuals from underrepresented racial and ethnic groups, individuals with disabilities, and individuals from socially, culturally, economically, or educationally disadvantaged backgrounds are especially encouraged to attend. Partial financial support for US participants from these groups is available by application to the local host, John Hewitt. Please contact Katie Sheehan for more information regarding partial financial support.

Financial support for this workshop is provided by Grant MH19918 from the National Institute of Mental Health. 